\title{
New found hope for antibiotic discovery: lipid II inhibitors
}

Vivian $\mathrm{Ng}^{[\mathrm{a}]}$ and Weng C. Chan ${ }^{\star[a]}$

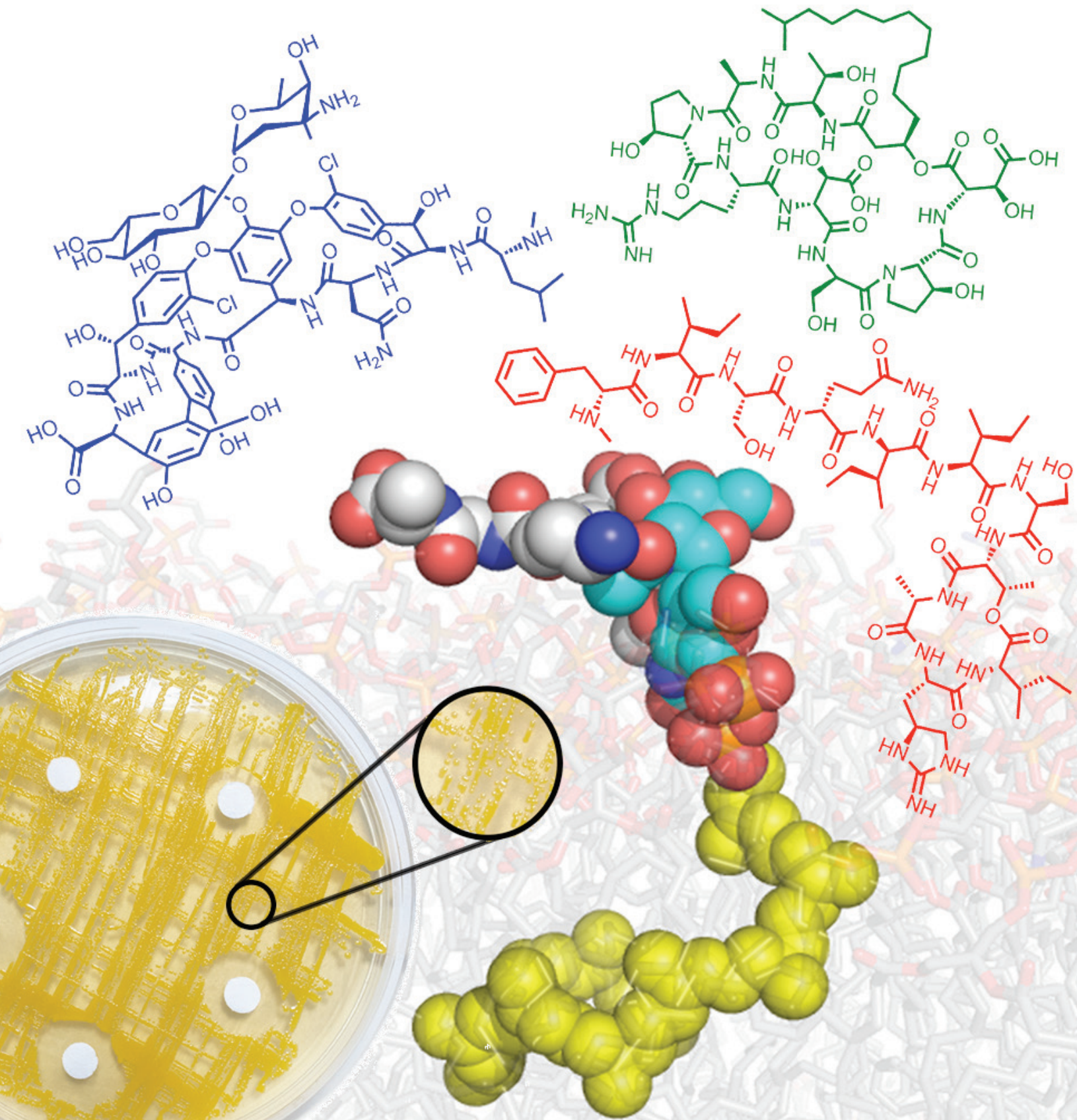




\section{Abstract:}

Research into antibacterial agents has recently gathered pace in light of the disturbing crisis of antimicrobial resistance. Development of modern tools offers opportunity of reviving the fallen era of antibacterial discovery through uncovering novel lead compounds that target vital bacterial cell components, such as lipid II. This paper provides a summary of the role of lipid II as well as an overview and insight into the structural features of macrocyclic peptides that inhibit this bacterial cell wall component. The recent discovery of teixobactin, a new class of lipid II inhibitor has generated substantial research interests. As such, the significant progress that has been achieved towards its development as a promising antibacterial agent is discussed.

\section{Introduction}

\subsection{Past, present and future of antibiotics}

For centuries, bacterial infections have troubled mankind and their history could be traced all the way back to ancient Egypt. Mouldy jam and bread were often used in folk medicine as poultice on wounds without understanding the antibacterial nature of moulds. ${ }^{[1]}$ In 1930s, the discovery of penicillin by Alexander Fleming heralded the dawn of a new era for controlling previously fatal bacterial infections, saving numerous lives. $^{[2]}$ Intensive research soon followed that led to the discovery of other antibiotics, such as streptomycin and tetracycline..$^{[3-5]}$ However, as predicted by Paul Ehrlich, resistance tends to follow a medicine development like a "faithful shadow". ${ }^{[6]}$ The widespread misuse of antibacterial agents have contributed to the emergence of resistant bacterial strains within just a few years after their clinical introduction. ${ }^{[5-8]}$

Antimicrobial resistance (AMR), which could be either intrinsic or acquired, remains an increasingly serious global threat with far-reaching clinical and cost implications. ${ }^{[3,9]}$ Clinically important antibiotic-resistant pathogens include Staphylococcus aureus, Pseudomonas aeruginosa and Enterococcus faecium. ${ }^{[10]}$ Treatment failure and prolonged illnesses inevitably lead to greater healthcare expenditure and higher mortality rate. ${ }^{[11]}$ On top of that, significant medical breakthroughs such as organ transplantation and invasive surgeries which rely heavily on the use of antibiotics are now threatened by AMR. ${ }^{[12]} \mathrm{A}$ recent evaluation of this crisis has estimated that AMR would lead to 300 million premature death and a global economic cost of $\$ 100$ trillion over the next three decades. ${ }^{[13,14]}$

Unfortunately, the situation is further complicated by a decline in the introduction of novel antibiotics (Figure 1). The "golden age" (1940s - 1960s) saw the discovery of most of the antibiotics in clinic today through exploitation of cultivable soil

[a] V. Ng, Dr W.C. Chan

School of Pharmacy, Centre of Biomolecular Sciences

University of Nottingham, University Park,

Nottingham, U.K., NG7 2RD.

E-mail: weng.chan@nottingham.ac.uk microbes (Waksman platform).$^{[15,16]}$ However, this era crumbled by the end of 1960s as no new compounds with significantly different molecular scaffold and/or mechanism-of-action from existing agents were uncovered from this limited resource of soil bacteria. ${ }^{[14,17]}$ Scientists began to employ synthetic approaches but bacterial cell envelopes have proven to be a huge hurdle for the synthetic compounds. ${ }^{[16,18]}$ Attempts to overcome cell membrane penetration and efflux issues by formulating sophisticated drug delivery systems have not yielded satisfactory clinical results. ${ }^{[12]}$ The unfavourable financial return eventually caused pharmaceutical companies to shift their research focus to other diseases. ${ }^{[10,14]}$ As feared by scientific community and healthcare professionals, the post-antibiotic age may now be upon us with the detection of pathogenic bacterial strains being resistant to colistin, the last antibiotic on the shelf. ${ }^{[12]}$

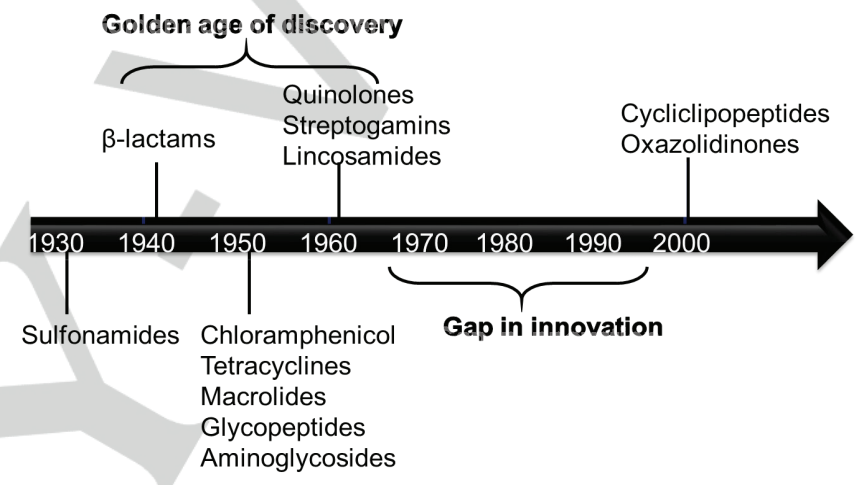

Figure 1. Antibiotic discovery timeline showing the golden era and the gap where no new structurally or functionally distinct antibiotics were found. ${ }^{[7,18]}$

Vivian $\mathrm{Ng}$ received her Masters in Pharmacy degree from the University of Nottingham in 2015. She is currently pursuing her Ph.D. degree under the supervision of Dr Weng Chan with research interests focusing on macrocyclic peptides as antibacterial agents.

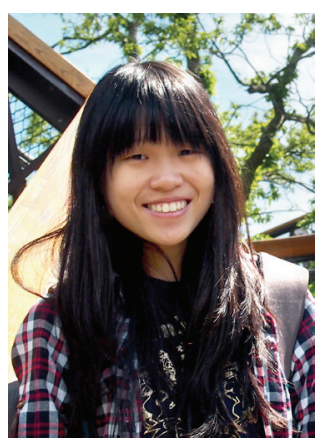

Weng C. Chan received his Ph.D. degree from the University of Nottingham in 1988, followed by postdoctoral training (1988-1992) under the guidance of Professors Barrie Bycroft and Gordon Roberts. He is currently Associate Professor and Reader in Chemical Biology and has published extensively in the area of solid-phase peptide chemistry, chemical biology and antibacterial agents, with over 85 papers, book chapters and patents. His research themes are focused on medicinal chemistry of macrocyclic

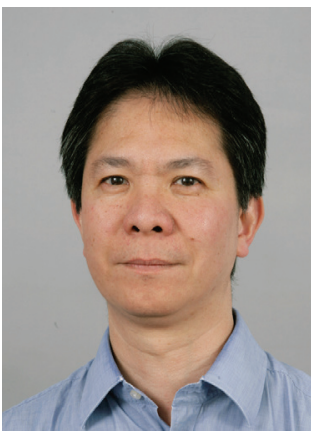
antimicrobials and the development of chemical tools for the biological studies of Gram-positive quorum sensing systems. 
Despite the seemingly discouraging circumstances, Ling et al. brought exciting news to address this global predicament through their work on uncultured bacteria. ${ }^{[16]}$ Over $99 \%$ of soil bacteria in nature are uncultured which reflects their inability to grow on laboratory media. ${ }^{[19]}$ These microbes thus represent an untapped reservoir of valuable compounds. ${ }^{[18,20]} \mathrm{A}$ multichannel device known as the isolation chip (iChip) ${ }^{[21]}$ was utilised by the research group to isolate and grow individual bacterial cell in miniature chambers. Prior to returning it to the soil, the device was covered with two semi-permeable membranes so that the cells could receive the environmental nutrients and growth factors needed for viability. Following incubation, the bacterial colonies were grown in vitro and their extracts were screened for antibacterial activity. The hard work paid off with the discovery of teixobactin which is isolated from a newly identified Gramnegative $\beta$-proteobacteria, Eleftheria terrae. ${ }^{[14,16,20,22,23]}$ Significantly, teixobactin is a potent inhibitor of lipid II, an essential component for the bacterial biosynthesis of crosslinked peptidoglycan. ${ }^{[16]}$

Therefore, all is not lost in the battle against bacterial infections as modern tools offer great opportunity to revive the old ways of discovering therapeutic compounds from the huge diversity of soil microorganisms. ${ }^{[18,21]}$ This mini-review thus provides an overview and an update on different classes of lipid II-targeting peptide antibiotics, particularly their chemical and structural aspects, as they are likely to revolutionise the treatment of bacterial infections.

\section{Targeting the central peptidoglycan synthesis}

\section{component of}

\subsection{Bacterial cell wall synthesis}

Bacterial cell wall, a unique structure crucial for cell survival and integrity, has long been validated as a prominent target for antimicrobials. ${ }^{[24,25]}$ Its main structural component known as peptidoglycan provides bacteria with the mechanical strength to withstand high intracellular osmotic pressure. ${ }^{[26,27]}$ Peptidoglycan is a polymer made up of linear chains of alternating $\mathrm{N}$ acetylglucosamine (GIcNAc) and $\mathrm{N}$-acetylmuramic acid (MurNAc) amino sugars coupled together by a $\beta-1,4-$ glycosidic bond. ${ }^{[28]}$ A pentapeptide domain, the sequence of which depends on the species of bacteria, is attached to the $\mathrm{N}$-terminal carboxyl moiety of the MurNAc sugar. ${ }^{[29-31]}$ The pentapeptide LAla-D-y-Glu-L-Lys-D-Ala-D-Ala is typically present in most Grampositive pathogens ${ }^{[30,32,33]}$ Cross-linking of the glycan chains is then achieved through sidechain-to-backbone amide bond formation between strands of pentapeptide domains. ${ }^{[34-36]}$

Bacterial cell wall biosynthesis is highly complex, with multiple components and numerous tightly coordinated enzymatic reactions (Figure 2). ${ }^{[34]}$ The two-stage process of peptidoglycan subunit synthesis begins with the assembly of UDP-MurNAc-pentapeptide precursor from UDP-GIcNAc through a series of steps catalysed by MurA-F synthetases in cytoplasmic side. ${ }^{[29]}$ UDP-MurNAc-pentapeptide is then transferred by MraY translocase to the 11-subunit membraneembedded undecaprenyl phosphate, thereby producing an intermediate called lipid I. Following the coupling of GIcNAc to lipid I, lipid II is formed which carries the complete peptidoglycan subunit (GIcNAc-MurNAc-pentapeptide) that is attached to undecaprenyl phosphate via a pyrophosphate moiety. ${ }^{[27,30,34]}$ During the second stage, lipid II is flipped by MurJ or FtsW flippase to the periplasmic side of inner membrane. ${ }^{[29,37,38]}$ Subsequently, lipid II is incorporated into growing cell wall through transglycosylation and transpeptidation reactions catalysed by the two catalytic domains of penicillin-binding proteins (PBPs) ${ }^{[35,39]}$ The released undecaprenyl pyrophosphate is then shuttled back to the cytosolic face where it is dephosphorylated back into its monophosphate form to be

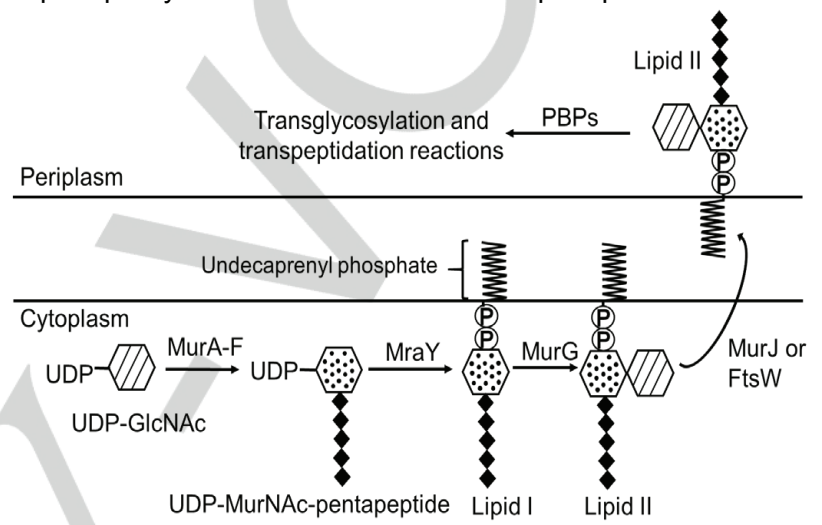

recycled for the next synthesis cycle. ${ }^{[27,34,40]}$

Figure 2. Bacterial cell wall synthesis involves a complex series of enzymatic reactions. Lipid I is produced when the assembled UDP-MurNAc-pentapeptide is attached to the membrane-embedded undecaprenyl phosphate. Another UDP-GICNAc molecule is transferred to lipid I, thus forming lipid II which is then flipped across the membrane to the periplasmic face where it can be incorporated into the peptidoglycan layer through transglycosylation and transpeptidation reactions.

\subsection{Lipid II as the therapeutic target}

Among the cell wall components, lipid II is one of the most highly sought-after targets for antimicrobials (Figure 3) ${ }^{[34,41]}$ Despite being an essential peptidoglycan precursor, a limited amount of lipid II can be synthesised at a time since there are only approximately $2 \times 10^{5}$ undecaprenyl phosphate molecules present in each cell. ${ }^{[30,42,43]}$ To keep up with the rapid growth of peptidoglycan layer, each lipid II molecule must have a high turnover rate. ${ }^{[4]}$ The lipid II cycle is thus considered to be the rate-limiting step in peptidoglycan biosynthesis, thereby making

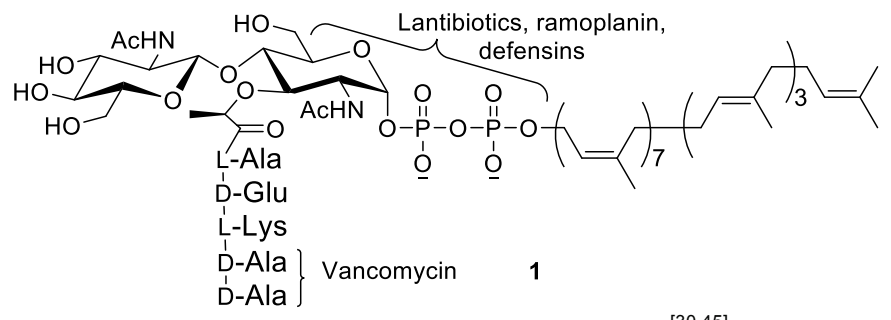

this lipid intermediate an attractive antibiotic target. ${ }^{[30,45]}$

Figure 3. The chemical structure of lipid II (1) and binding sites of several lipid II inhibitors. The pentapeptide sequence in Gram-positive bacteria is shown. 
The localisation of lipid II on the outside of bacterial cytoplasmic membrane allows it to be easily targeted by antimicrobial agents. In addition, its structural complexity offers several potential binding sites for antibiotics. ${ }^{[27]}$ The pentapeptide domain apparently adopts an upright position and points away from the surface of phospholipid bilayer. ${ }^{[44]}$ Meanwhile, the anchoring of its undecaprenyl phosphate in the membrane strategically places the negatively-charged pyrophosphate at the bilayer interface where ionic interactions with positively-charged residues or compounds can be easily formed. ${ }^{[17]}$ These groups therefore serve as attractive binding motifs for lipid II inhibitors. ${ }^{[4]]}$ Furthermore, lipid II composition is unique within the bacterial kingdom, thereby preventing possible toxic effect of lipid II binders on mammalian cells. ${ }^{[27,46,47]}$

Research with lipid II was initially restricted by its low abundance and the laborious isolation and purification processes involved. ${ }^{[48,49]}$ However, the availability of membrane enzymes and the attractiveness of lipid II as an antimicrobial target have driven the development of chemical, chemoenzymatic and enzymatic strategies to prepare lipid II. ${ }^{50-}$ ${ }^{53]}$ The enzymatic approach utilises MraY and MurG activities of membrane preparations to synthesise lipid II in the presence of undecaprenyl phosphate, UDP-MurNAC-pentapeptide and UDPGIcNAc. As both enzymes have narrow substrate specificity, this method is highly effective and can be easily scaled up. ${ }^{[50,53,54]}$ On the other hand, chemical synthesis enables various structural alterations of lipid II that cannot be achieved with MraY and MurG ${ }^{[51,52]}$ Its main drawback is the costly chemical reagents. Alternatively, a combination of chemical and enzymatic procedures can be utilised whereby purified MurG is used to convert chemically-synthesised lipid I to lipid II. ${ }^{[5,55]}$ The development of these methods for the preparation of lipid II facilitates the identification and detailed studies of lipid II inhibitors; the choice of preparation of lipid II relies primarily on the lipid II variant that is needed. ${ }^{[54]}$ The interaction of antibacterial agents with lipid II can then be investigated via coincubation of these compounds with the purified lipid II, followed by extraction and analysis using thin-layer chromatography. ${ }^{[16,56]}$

\section{Lipid II inhibitors as therapeutic agents}

\subsection{Progress over the last 60 years}

The highly dynamic lipid II is the target of several classes of antibiotics that home in on different parts of the molecule. ${ }^{[25,30,34,57]}$ The first discovered example of lipid II inhibitor is vancomycin 2, a glycopeptide which is used as the last-line treatment for problematic Gram-positive organisms, such as methicillin-resistant $S$. aureus (MRSA) ${ }^{[58]}$ As shown in Figure 4 , it binds to the C-terminal D-Ala-D-Ala of the pentapeptide. ${ }^{[59,60]}$ By forming a stable complex with lipid II through five hydrogen bonds and hydrophobic interactions, vancomycin sterically shields this lipid intermediate from PBPs and prevents its subsequent incorporation into the growing peptidoglycan network. ${ }^{[61,62]}$ Bacteria eventually succumb to the high internal osmotic pressure due to weakened cell wall. ${ }^{[1]}$ However, despite the initial excitement of vancomycin being effective against resistant bacteria when it was introduced in 1953, vancomycin-insensitive strains have now surfaced through horizontal gene transfer. ${ }^{[22,63]}$ The clinical resistance can be attributed to operons encoding proteins that mediate the enzymatic replacement of terminal D-Ala with D-Lac or D-Ser, producing low-affinity peptidoglycan building blocks. ${ }^{[63,64]}$ The resulting D-Ala-D-Lac and D-Ala-D-Ser dipeptide motifs reduce the affinity of vancomycin through the loss of a crucial hydrogen bond and the formation of steric hindrance, respectively. ${ }^{[3,62,65,66]}$

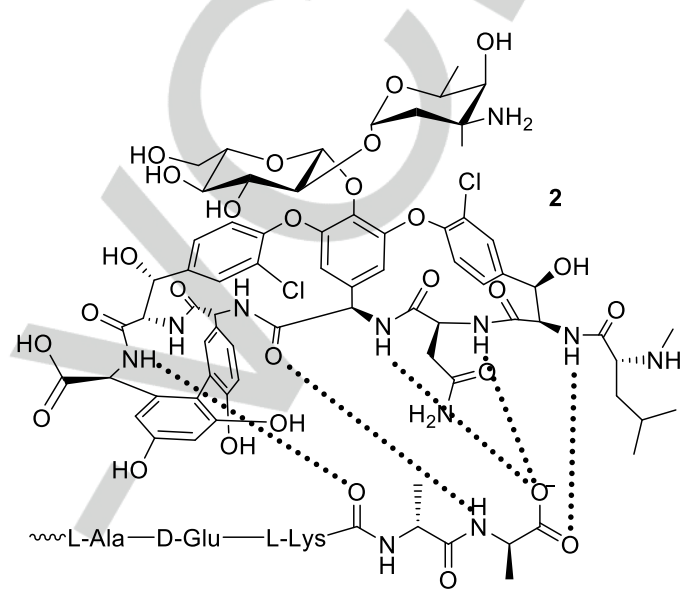

Figure 4. Hydrogen bonds (dotted lines) between vancomycin (2) and D-AlaD-Ala of lipid II. ${ }^{[62]}$

The clinical challenges of vancomycin-resistant staphylococci and enterococci raised research interests into semisynthetic glycopeptide variants, such as oritavancin and telavancin, which also bind to the $\mathrm{C}$-terminus dipeptide. ${ }^{[67,68]}$ These agents, however, contain extra hydrophobic residues which increase their amphiphilicity. ${ }^{[34]}$ For example, oritavancin 3 carries both 4-epi-vancosamine and 4'-chlorobiphenyl methyl moieties that form additional interactions with the peptidyl cross bridge and $D-\gamma-G$ In of lipid II, thus compensating for the lost hydrogen bond observed in vancomycin-resistant strains (Figure 5). ${ }^{[62,69]}$ As such, oritavancin showed enhanced antibacterial potency against MRSA and other vancomycin-insensitive bacteria. ${ }^{[70,71]}$

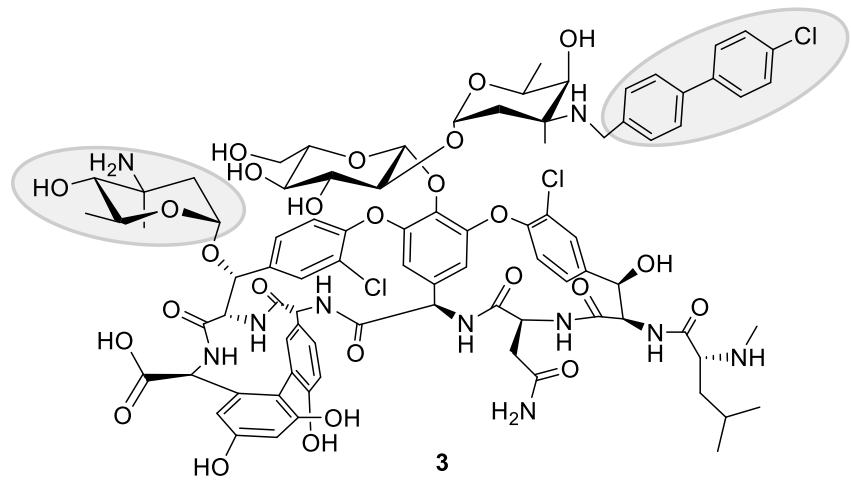

Figure 5. Chemical structure of oritavancin (3), with its extra hydrophobic side chains. 
Besides that, the issue with vancomycin resistance revealed binding sites that are prone to mutations and highlighted the need for antibiotics that exploit other less modifiable domains of lipid II. $^{[72]}$ One important class of such agents is the lantibiotics, a group of peptides with the characteristic lanthionine and/or methyllanthionine moieties. ${ }^{[73-75]}$ They can be further divided into two subtypes. Type $A$ lantibiotics are elongated and positively charged whereas type $B$ agents are globular compounds which are either slightly negatively charged or non-charged under neutral condition. ${ }^{[76,77]}$

Nisin, a type A lantibiotic produced by Lactococcus lactis, has been used as natural food preservative for decades. ${ }^{[40,78]}$ Hsu et al. ${ }^{[26]}$ have shown that the first ten $\mathrm{N}$-terminal amino acid residues of its rings $A$ and $B$ form a cage that envelopes the pyrophosphate linkage of lipid II instead of the vancomycintargeted pentapeptide domain. Intermolecular hydrogen bonds between the pyrophosphate and the amide backbone of the rings lock lipid II in a stable complex, thus halting the entire peptidoglycan synthesis. ${ }^{[26,34,56]}$ The primary structure of nisin and its structure-activity relationship (SAR) with lipid II are depicted in Figure 6. However, rings A-B are inactive on their own. ${ }^{[79]}$ It is suggested that upon pyrophosphate cage formation, the rings $\mathrm{C}-\mathrm{E}$ (C-terminus) of nisin insert into the lipid bilayer, thereby facilitating the assembly of nisin-lipid II pore complex which leads to the lysis of bacteria. ${ }^{[40,80-82]}$ This dual mechanismof-action makes nisin a very potent Gram-positive antibacterial agent. Unfortunately, the poor pharmaceutical properties of native nisin, such as sensitivity to proteolytic enzymes and poor solubility beyond $\mathrm{pH} 6$, limit its clinical uses. ${ }^{[73,77]}$ Semisynthetic analogues have been developed whereby the C-E domain of the natural product was replaced with various lipid substituents. Several of these derivatives which showed enhanced proteolytic stability and potent antibacterial activity hold great therapeutic promise. $^{[82]}$
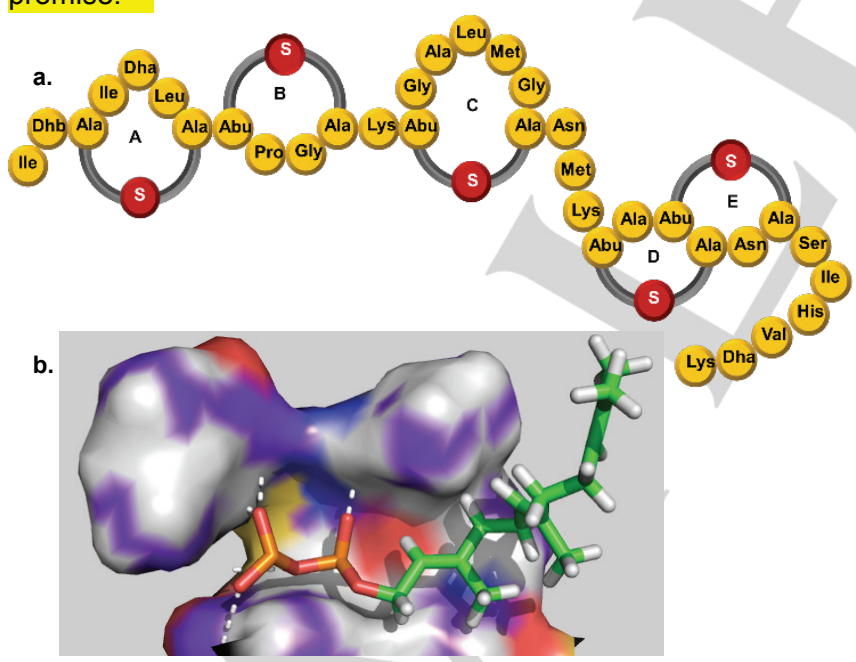

Figure 6. (a) Primary structure of nisin. (b) The residues of rings A and B of nisin envelope the pyrophosphate group of a lipid II variant, with intermolecular hydrogen bonds illustrated as white dashes. ${ }^{[26]}$ The solution structure of nisinlipid II complex was obtained from Research Collaboratory for Structural Bioinformatics (RCSB) Protein Data Bank (PDB ID: 1WCO) and the figure was generated using PyMOL (http://www.pymol.org/). Abu, aminobutyric acid; Dha, didehydroalanine; Dhb, didehydrobutyrine.
The modes of action of other lantibiotics and cyclic peptides, such as ramoplanin and enduracidin, have been extensively reviewed in various literature. ${ }^{[17,34,83-88]}$

Lipid II inhibition is also achieved by defensins, a large group of endogenous peptides expressed in a wide range of organisms. They form the host epithelial defense system. ${ }^{[89,90]}$ For instance, Schneider et al. demonstrated that plectasin, a defensin isolated from a saprophytic fungus Pseufoplectania nigrella, disrupts cell wall biosynthesis through binding to lipid II. ${ }^{[91,92]}$ Defensins from fungi, invertebrates such as maggots and mussels, and humans have shown similar antimicrobial activity. ${ }^{[46,93,94]}$ These studies not only firmly support lipid II as a valuable therapeutic target, but also suggest alternative resources of discovering novel antibacterial agents.

\subsection{Teixobactin as a promising lipid II inhibitor}

The aforementioned teixobactin has been reported to be the first of a new class of lipid II inhibitors that interacts mainly with the pyrophosphate and first sugar moiety of the molecule. Although lipid II is its predominant target, teixobactin also acts on lipid III (undecaprenyl-pyrophosphate-GIcNAc) which plays a pivotal role in the synthesis of another cell wall component called teichoic acid. ${ }^{[3,16]}$ This may lead to the release of autolysins which are anchored by teichoic acid under normal circumstances. ${ }^{[95]}$ Autolysin-mediated digestion of peptidoglycan layers that eventually results in bacterial lysis has therefore been proposed as another mode of action of this antibacterial agent. ${ }^{[16,96]}$ As such, teixobactin has demonstrated potent in vitro and in vivo bactericidal activity. ${ }^{[16]}$

Structural studies have revealed teixobactin 4 as a cyclic tetradepsipeptide that comprises 11 amino acids, four of which are of D-configuration (Figure 7). Apart from N-methyl-Dphenylalanine, it contains an unusual amino acid known as Lallo-enduracididine. The variants of this amino acid can also be found in enduracidin and mannopeptimycin. ${ }^{[16,87,97,98]}$ The SARs of teixobactin and its lipid targets, however, remain to be addressed. Also, there are still very little preclinical investigations to date for this cyclic depsipeptide and so these preliminary results should be interpreted with caution to avoid possible bias.

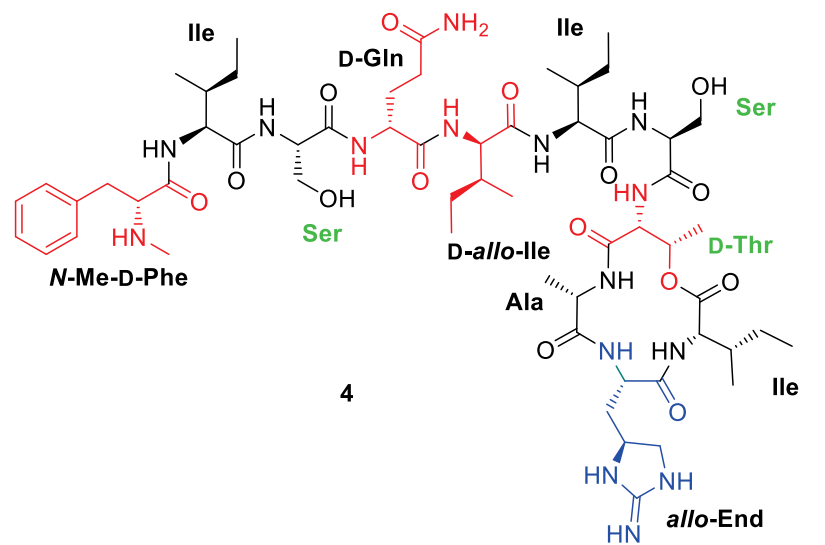

Figure 7. Chemical structure of teixobactin (4), with D-amino acids (red), $\beta$ hydroxy amino acids (green) and the unusual enduracididine highlighted (blue). 
Its excellent activity against resistant bacterial strains and the lack of resistance have stimulated tremendous research interests in developing teixobactin into a therapeutic agent. ${ }^{[16]}$ In less than a year after its discovery, the first total synthesis of its analogue by solid-phase peptide synthesis has been successfully executed. Here, the L-allo-enduracididine residue found in teixobactin is replaced with the readily available LArg. ${ }^{[99]}$ Intramolecular cyclisation, an intrinsically slow process susceptible to side-reactions such as dimerisation and epimerisation of $\alpha-C$ on $C$-terminus, is the main synthetic hurdle for all cyclic peptides. ${ }^{[100,101]}$ Following careful consideration of cyclisation position and coupling reagents, Albericio and his coworkers accomplished macrolactamisation of the protected peptide in just one day by using PyAOP/OxymaPure/DIEA without side-reactions (Figure 8). However, their synthetic attempt was not without setback. The symmetrical anhydride method employed for the esterification between D-Thr and L-lle required several couplings to attain $97 \%$ conversion. Nevertheless, several problems were avoided with the realisation that it was necessary to couple two additional amino acids onto D-Thr prior to the esterification of its hydroxyl group, in order to prevent $\mathrm{O} \rightarrow \mathrm{N}$ acyl migration during deprotection of Fmoc from D-Thr. Undesirable formation of diketopiperazine was also prevented by protecting the N-terminus of both L-Ile and LArg with an Alloc protecting group instead of Fmoc. ${ }^{[99]}$ With further optimisation of the esterification step, this synthetic strategy would represent a significant advancement. Importantly, the Arg-analogue obtained displayed similar antibacterial activity as teixobactin ${ }^{\left[{ }^{[9]}\right.}$ Its slight inferior potency against $S$. aureus and $B$. subtilis compared to teixobactin must then be attributed to the L-Arg residue, implying that a constrained guanidino-based side chain with additional chirality is better than its flexible counterpart.

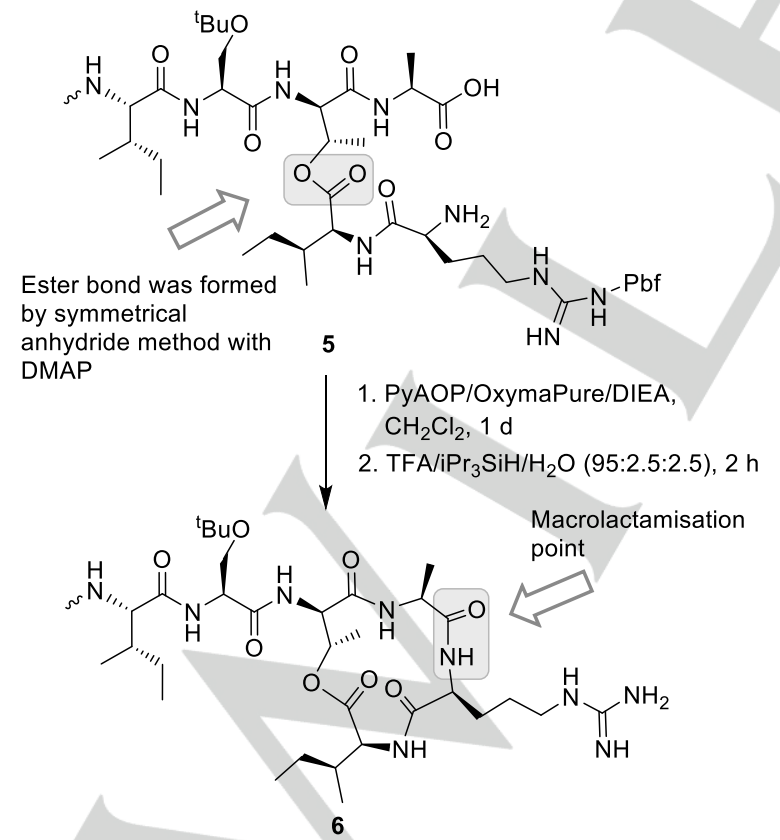

Figure 8. Esterification and macrolactamisation performed by Albericio and his co-workers to obtain a teixobactin analogue.
The remaining hurdle to the total synthesis of the natural product is then the availability of the unusual amino acid L-alloenduracididine. The presence of enduracididine in several prominent peptides has inspired effort to devise its synthesis from simple precursors. ${ }^{[102-104]}$ Achieving the correct chirality at C4 is the primary difficulty in synthesising this amino acid. ${ }^{[103]}$ The earliest reported strategy utilised Bamberger cleavage of methyl L-histidinate and subsequent hydrogenation to give a 1:1 mixture of $(2 S, 4 R)$-enduracididine and its $(2 S, 4 S)$ diastereomer. ${ }^{[105]}$ Other research groups undertook alternative methods of synthesising the amino acid from commercially available allylglycine, namely one-pot iminoiodane-mediated tandem aziridation and ring-opening reaction, as well as $\mathrm{Rh}$ catalysed approach. However, neither diasteroselectivity nor yield was satisfactory. ${ }^{[102,104]}$ The situation may have been turned around as Craig et al. have succeeded in developing a method with desirable stereoselectivity $(\mathrm{dr}>50: 1)$ and scalability. The required chirality of $\mathrm{C} 4$ was obtained through inversion of the hydroxyl group of trans-hydroxyproline 7 by mesylation and azide substitution to afford the azido-derivative $\mathbf{8}$ as shown in Figure 9. Although 10 steps were involved, the high diastereoselectivity ensured that the yield of the desired diastereomer was not compromised. ${ }^{[103]}$

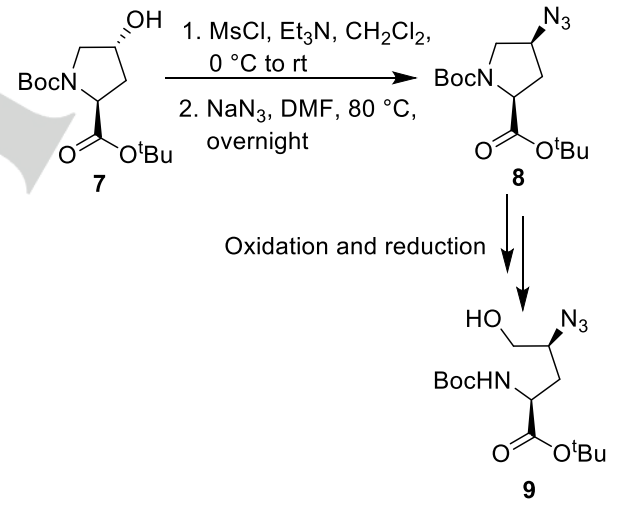

Figure 9. The key mesylation and azide substitution steps that established the chirality of C4.

With tremendous progress in the synthetic strategies for enduracididine and teixobactin analogue, the total synthesis of the naturally occurring teixobactin would soon be within the grasp of scientific community.

\subsection{An insight into the structures of teixobactin and other lipid II binders}

Until recently, the different classes of lipid II binders have been regarded as having no significant structural similarities. ${ }^{[17,58]}$ However, a closer examination of the chemical structures of teixobactin (Figure 7) and other lipid II binders including ramoplanin $A 2$, enduracidin $A$, katanosin $B$ and plusbacin $A 3$ (Figure 10) showed that lipid II is generally favoured by cyclic peptides. ${ }^{[30,87,88,106,107]}$ In contrast to linear peptides, the conformational restriction of cyclic structures contributes to better metabolic stability and improved target binding affinity. ${ }^{[108]}$ 
Also, the macrocyclic peptides 10, 11 and 13 (Figure 10) possess lipophilic side chains which are vital for their antimicrobial activities, possibly through membrane insertion or hindering PBPs from reaching lipid II. ${ }^{[17,107]} \mathrm{A}$ noticeable structural difference is the unique dimannosyl group that is present only in ramoplanin A2 $\mathbf{1 0}$, which is likely to provide enhanced hydrolytic stability and solubility. ${ }^{[87,109,110]}$

Interestingly, in the case of mannopeptimycins, a class of cyclic glycopeptide isolated from Streptomyces hygroscopicus $L L-A C 98,{ }^{[111]}$ an acyl dissacharide moiety O-tethered to a tyrosine residue appeared to be crucial for antibacterial activity. Its most potent member, mannopeptimycin $\varepsilon$ consists of a cyclic hexapeptide core. Importantly, its D-Tyr residue is Oglycosylated with a dimannosyl moiety carrying an isovaleryl group at the C4 position of terminal mannose ring while its $\beta$ $\mathrm{OH}-\mathrm{D}$-allo-enduracididine residue has an $\mathrm{N}$-linked mannose group (Figure 11). ${ }^{[98,112-114]}$ Singh et al. demonstrated that mannopeptimycin $\beta$ which lacks both the isovaleryl and dissacharide displayed poor in vitro and in vivo activity. ${ }^{[111]}$ Further investigations revealed that the isovaleryl moiety is also vital for antibacterial activity. ${ }^{[115]}$ Research began to focus on preparation of semisynthetic analogues with modifications mainly on this disaccharide side chain. ${ }^{[113-117]}$. Moreover, the replacement of both enduracididine residues of a mannopeptimycin aglycone analogue with L- and D-Arg demonstrated a notable reduction in antimicrobial effect: ${ }^{[118]}$ a similar detrimental effect was observed when the enduracididine residue in teixobactin was replaced with $A r g .{ }^{[99]}$ As limited SAR studies are currently available, the key structural requirements of lipid II inhibitors remain to be established.

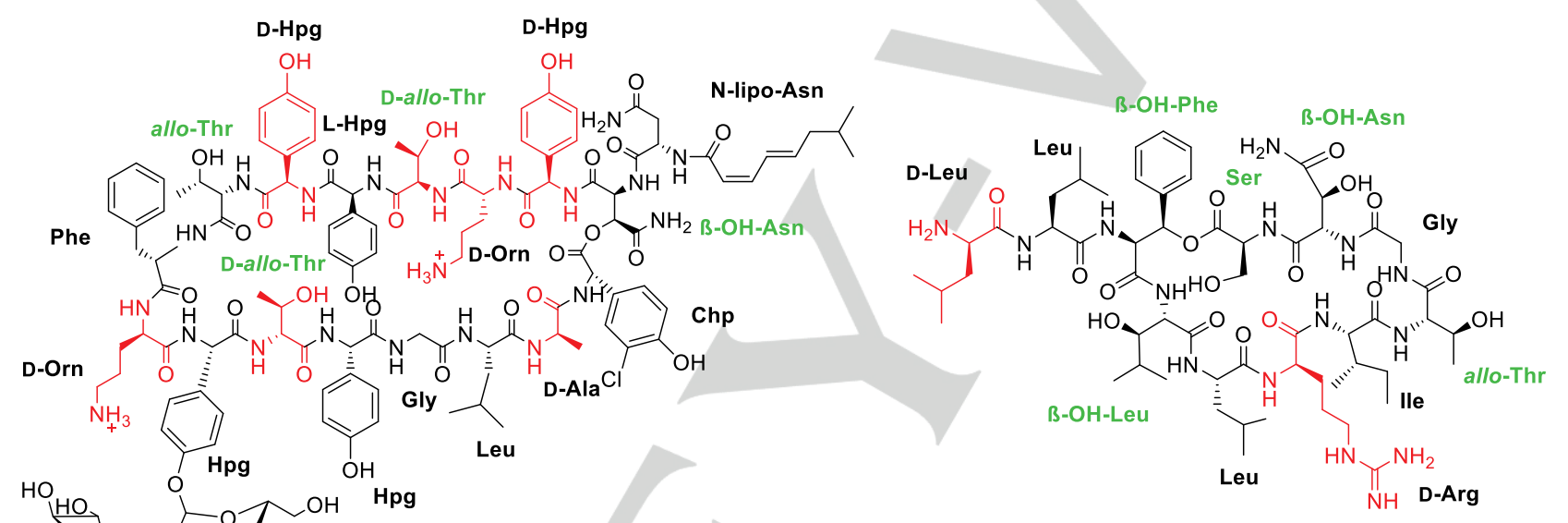

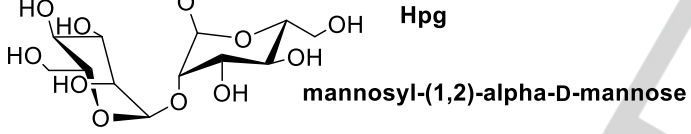

10
12

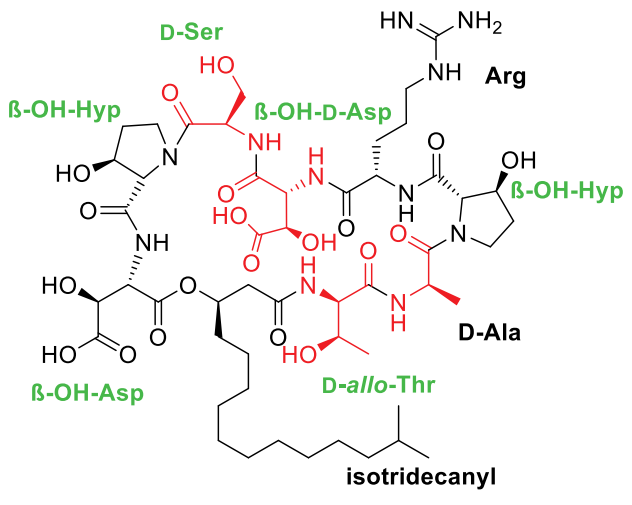

13

Figure 10. Chemical structures of ramoplanin A2 (10), enduracidin A (11), katanosin $B$ (12), and plusbacin A3 (13), with D-amino acids (red), $\beta$-hydroxy amino acids (green), and enduracididine (blue) highlighted. Orn, ornithine; Hpg, 4-hydroxyphenylglycine; Dpg, 3,5-dichloro-4-hydroxyphenylglycine; Cit, citrulline. 


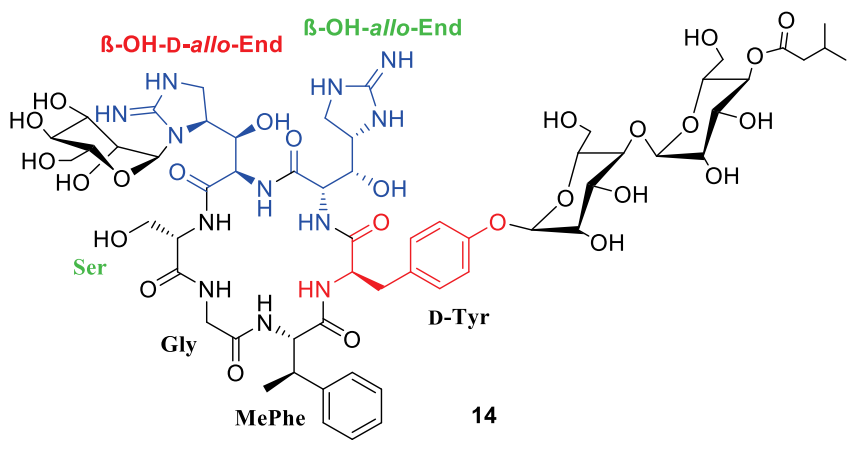

Figure 11. Chemical structure of mannopeptimycin $\varepsilon$ (14), showing D-amino acid (red), $\beta$-hydroxy amino acids (green) and enduracididine (blue).

Nevertheless, other common structural features can still be seen in these peptides. As the lipid components of bacterial cell walls are negatively charged, antibacterial agents are typically cationic and amphiphilic to facilitate effective charged-mediated binding interactions. ${ }^{[34,119]}$ For instance, the guanidine side chain of teixobactin and katanosin $B$ as well as the ornithine residue of ramoplanin are positively charged. ${ }^{[83,106,120]}$ Another evidence came from a study by Fletcher et al. which demonstrated that the positively charge pyrylium moiety of a small molecule inhibitor BAS00127538 15 (Figure 12) was essential in forming ionic interactions with the phosphate group. ${ }^{[58]}$ Apart from the pyrylium ring, its indolene and two phenyl rings are predicted to interact with the hydrophobic undecaprenyl residues and the MurNAc of lipid II, respectively. ${ }^{[58,121]}$

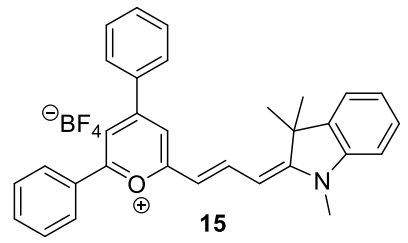

Figure 12. BAS00127538, a small molecule lipid II inhibitor (15)

Recently, in an attempt to identify transglycosylase inhibitors through in silico followed by in vitro biochemical screens, a lipid II inhibitor was unexpectedly discovered. ${ }^{[122]}$ This lipid II inhibitor is a tryptamine-containing molecule 16 (Figure 13). Biological evaluation on a subset of related analogues showed that the replacement of the amine group with a guanidine moiety improved their lipid II-binding ability. ${ }^{[123]}$ These compounds thus serve as valuable leads for further optimisation and development of novel low molecular weight lipid II inhibitors. Over the years, there has been a growing interest in peptide antibacterial agents over small molecules as peptides generally exhibit better target specificity and a lower risk of systemic toxicity. ${ }^{[124,125]}$
Besides that, all of the lipid II inhibitors discussed above contain D-amino acids and/or non-proteinogenic amino acids which are often synthesised by bacteria. ${ }^{[126]}$ Their presence confers improved in vivo protease stability to these antimicrobial peptides, thereby overcoming pharmacokinetic issues such as short half-life and poor oral bioavailability that often thwart the therapeutic applications of peptides with only naturally occurring amino acids. ${ }^{[27,128]}$

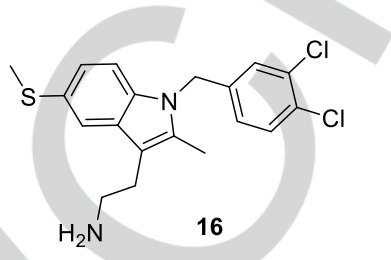

Figure 13. The tryptamine-containing lead compound discovered through in silico screening that binds to lipid II (16).

Interestingly, as pointed out by von Nussbaum et al. ${ }^{[106]}$, teixobactin 4 is structurally similar to hypeptin 17 , an octapeptide isolated in 1989 from a strain of Pseudomonas sp. Hypeptin also showed good antibacterial activity against $S$. aureus. ${ }^{[129]}$ Apart from the same 13-membered ring size, hypeptin possesses similar shape and amino acid composition as teixobactin, with three L-amino acids and one D-amino acid involved in the formation of the cyclic ring. ${ }^{[106]}$ The only major difference is that hypeptin has a shorter exocyclic linear peptide chain. Nevertheless, it can be seen from Figure 14 that the first two amino acids of hypeptin (Ala-D-Leu) are both aliphatic which are comparable to the aliphatic dipeptide in teixobactin (D-allo-IleIle), thereby suggesting their role in forming hydrophobic interactions with lipid II. $\beta$-Hydroxy amino acids are also a characteristic feature of these cyclic peptides. In fact, half of the amino acids of hypeptin are $\beta$-hydroxylated. These structural resemblances have led to suggestion that hypeptin might also interact with lipid II. ${ }^{[106]}$

Amidst the excitement around teixobactin 4, there are concerns that resistance would ultimately emerge especially if the trend of inappropriate antimicrobial use remained widespread. Possible resistance mechanisms include secretion of antibiotic-modifying enzymes and thickening of bacterial cell wall that impedes the access of teixobactin to its lipid II target. ${ }^{[23]}$ It is also uncertain if resistance is already in existence in nature ${ }^{[16]}$ However, this should not be a major concern since the producer of teixobactin is a Gram-negative pathogen and so it is unlikely to have transferred its intrinsic resistance mechanisms to its Gram-positive counterparts. ${ }^{[20,23]}$ Additionally, it has been proposed that unlike other resistance mechanisms that involve efflux pumps and enzymes mutations, resistance to lipid II binders does not occur readily due to the difficulty in modifying a component that is biosynthesised in multiple steps. ${ }^{[30,130,131]}$ As lipid II is a unique non-protein target that cannot be easily altered by simple gene mutations especially at its pyrophosphate and lipid portions, resistance towards teixobactin is unlikely to develop at least for the next few decades. ${ }^{[20,23,47]}$ 
<smiles>CCC(C)[C@H](C=O)NC(=O)[C@H](Cc1ccccc1)NC</smiles>

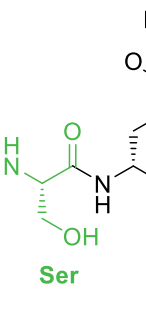

\section{D-GIn}<smiles>CC(N)=O</smiles>

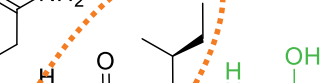

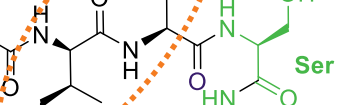

N-Me-D-Phe

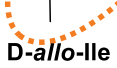<smiles>CC(=O)CC(C)C[Te]Br</smiles>
Ala

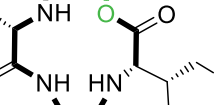

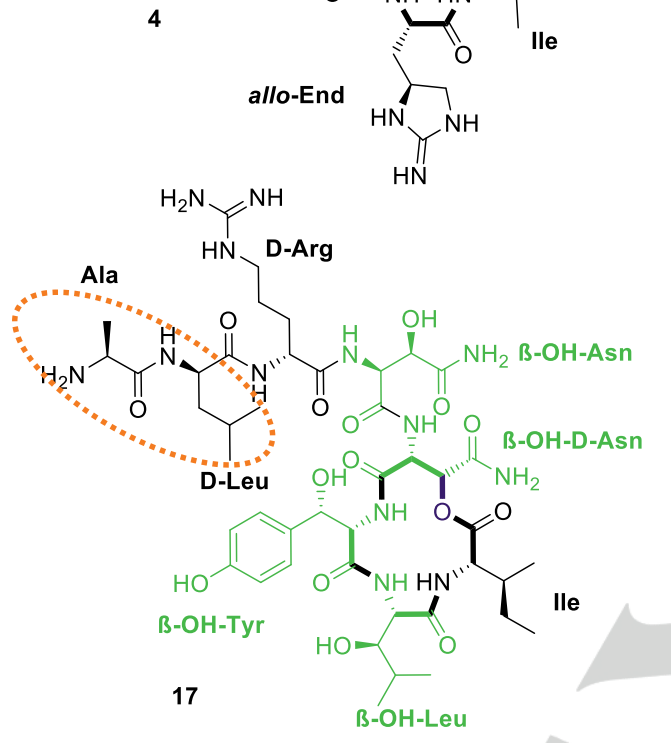

Figure 14. Structural resemblances between teixobactin (4) and hypeptin (17) with the same ring size as well as similar alipathic dipeptides (circle) and $\beta$ hydroxy amino acids (green).

\section{Summary and Outlook}

AMR is a prevalent global issue that has significant human and financial implications. Apart from curbing the misuse of antibiotics, intensive research into finding new antibiotics is of utmost importance to address the current unmet treatment needs for resistant bacterial strains. The enhanced appreciation of the molecular basis of cell wall biosynthetic pathways and the development of modern tools to explore uncultured soil bacteria provide hopes for discovering novel antibacterial agents.

Lipid II has been validated as a prominent molecular target and various lipid II binders with substantial structural diversity have emerged. As great progress has been made and more medicinal chemistry research projects would soon unfold, the battle against bacterial infections might not be lost. The antibacterial efficacy of teixobactin especially against resistant strains offers promise of further clinical applications once proper validation studies have been carried out. However, its current lack of resistance could not be taken for granted and the power of evolution should not be underestimated as resistance might surface during its clinical usage period.

Acknowledgement: We would like to acknowledge financial support from Vice-Chancellor's Scholarship for Research Excellence, University of Nottingham (to VN). We thank $\mathrm{Dr}$ Anton Chugunov for the structure file of lipid II which we used to generate the figure (using PyMOL) in the frontispiece and the graphical abstract (table of contents).

Keywords: lipid II inhibitors $•$ macrocyclic peptides $•$ antibiotics •

[1] M. Wainwright, Mycologist 1989, 3, 21-23.

[2] S. A. Alharbi, M. Wainwright, T. A. Alahmadi, H. Bin Salleeh, A. A. Faden, A. Chinnathambi, Saudi J. Biol. Sci. 2014, 21, 289-93.

[3] A. Penesyan, M. Gillings, I. T. Paulsen, Molecules 2015, 20, 528698.

[4] N. Kardos, A. L. Demain, Appl. Microbiol. Biotechnol. 2011, 92, 677-87.

[5] C. M. Kunin, Ann. Intern. Med. 1993, 118, 557.

[6] G. J. Ebrahim, J. Trop. Pediatr. 2010, 56, 141-3.

[7] C. T. Walsh, T. A. Wencewicz, J. Antibiot. (Tokyo). 2014, 67, 7-22.

[8] M. L. Cohen, Science 1992, 257, 1050-1055.

[9] A. J. Alanis, Arch. Med. Res. 2005, 36, 697-705.

H. W. Boucher, G. H. Talbot, D. K. Benjamin, J. Bradley, R. J. Guidos, R. N. Jones, B. E. Murray, R. A. Bonomo, D. Gilbert, Clin. Infect. Dis. 2013, 56, 1685-94.

F. C. Tenover, Am. J. Med. 2006, 119, S3-10; discussion S62-70. E. D. Brown, G. D. Wright, Nature 2016, 529, 336-343. J. O'Neill, Rev. Antimicrob. Resist. 2014, 1-16.

C. A. Arias, B. E. Murray, N. Engl. J. Med. 2015, 372, 1168-70. R. I. Aminov, Front. Microbiol. 2010, 1, 134.

[16] L. L. Ling, T. Schneider, A. J. Peoples, A. L. Spoering, I. Engels, B. P. Conlon, A. Mueller, D. E. Hughes, S. Epstein, M. Jones, et al., Nature 2015, 517, 455-459.

J. B. Hamburger, A. J. Hoertz, A. Lee, R. J. Senturia, D. G. McCafferty, P. J. Loll, Proc. Natl. Acad. Sci. U. S. A. 2009, 106, 13759-64.

[18] K. Lewis, Nature 2012, 485, 439-40.

[19] Y. Wang, Y. Chen, Q. Zhou, S. Huang, K. Ning, J. Xu, R. M. Kalin, S. Rolfe, W. E. Huang, PLoS One 2012, 7, e47530.

[20] C. T. Kåhrström, Nat. Rev. Microbiol. 2015, 13, 126-127.

[21] D. Nichols, N. Cahoon, E. M. Trakhtenberg, L. Pham, A. Mehta, A. Belanger, T. Kanigan, K. Lewis, S. S. Epstein, Appl. Environ. Microbiol. 2010, 76, 2445-50. G. Wright, Nature 2015, 517, 442-4.

[23] A. Kali, J. Clin. Diagn. Res. 2015, 9, DL01.

[24] A. L. Koch, Clin. Microbiol. Rev. 2003, 16, 673-87.

[25] A. Chugunov, D. Pyrkova, D. Nolde, A. Polyansky, V. Pentkovsky, R. Efremov, Sci. Rep. 2013, 3, 1678.

[26] S.-T. D. Hsu, E. Breukink, E. Tischenko, M. A. G. Lutters, B. de Kruijff, R. Kaptein, A. M. J. J. Bonvin, N. A. J. van Nuland, Nat. Struct. Mol. Biol. 2004, 11, 963-7.

B. de Kruijff, V. van Dam, E. Breukink, Prostaglandins. Leukot. Essent. Fatty Acids 2008, 79, 117-21.

[28] H. Harz, K. Burgdorf, J.-V. Höltje, Anal. Biochem. 1990, 190, 120- 
128.

[29] J. van Heijenoort, L. Gutmann, Proc. Natl. Acad. Sci. U. S. A. 2000, 97, 5028-30.

[30] E. Breukink, B. de Kruijff, Nat. Rev. Drug Discov. 2006, 5, 321-32.

[31] S. O. Meroueh, K. Z. Bencze, D. Hesek, M. Lee, J. F. Fisher, T. L. Stemmler, S. Mobashery, Proc. Natl. Acad. Sci. U. S. A. 2006, 103, 4404-9.

[32] A. J. F. Egan, J. Biboy, I. van't Veer, E. Breukink, W. Vollmer, Philos. Trans. R. Soc. B Biol. Sci. 2015, 370, 20150031.

[33] J. Humann, L. L. Lenz, J. Innate Immun. 2009, 1, 88-97.

[34] D. Münch, H.-G. Sahl, Biochim. Biophys. Acta 2015, 1848, 30623071.

[35] D.-J. Scheffers, M. G. Pinho, Microbiol. Mol. Biol. Rev. 2005, 69, 585-607.

[36] J. L. Strominger, D. J. Tipper, Am. J. Med. 1965, 39, 708-721.

[37] L.-T. Sham, E. K. Butler, M. D. Lebar, D. Kahne, T. G. Bernhardt, N. Ruiz, Science 2014, 345, 220-2.

[38] T. Mohammadi, V. van Dam, R. Sijbrandi, T. Vernet, A. Zapun, A. Bouhss, M. Diepeveen-de Bruin, M. Nguyen-Distèche, B. de Kruijff, E. Breukink, EMBO J. 2011, 30, 1425-32.

[39] H.-W. Shih, Y.-F. Chang, W.-J. Li, F.-C. Meng, C.-Y. Huang, C. Ma, T.-J. R. Cheng, C.-H. Wong, W.-C. Cheng, Angew. Chem. Int. Ed. Engl. 2012, 51, 10123-6.

[40] E. Breukink, B. de Kruijff, Biochim. Biophys. Acta - Biomembr. 1999 1462, 223-234.

[41] S. F. Oppedijk, N. I. Martin, E. Breukink, Biochim. Biophys. Acta Biomembr. 2016, 1858, 947-957.

[42] N. E. Kramer, E. J. Smid, J. Kok, B. de Kruijff, O. P. Kuipers, E. Breukink, FEMS Microbiol. Lett. 2004, 239, 157-61.

[43] D. R. Storm, J. L. Strominger, J. Biol. Chem. 1974, 249, 1823-7.

[44] D. N. Ganchev, H. E. Hasper, E. Breukink, B. de Kruijff, Biochemistry 2006, 45, 6195-202.

[45] T. Mascher, S. L. Zimmer, T.-A. Smith, J. D. Helmann, Antimicrob. Agents Chemother. 2004, 48, 2888-96.

[46] A. Essig, D. Hofmann, D. Münch, S. Gayathri, M. Künzler, P. T. Kallio, H.-G. Sahl, G. Wider, T. Schneider, M. Aebi, J. Biol. Chem. 2014, 289, 34953-64.

[47] B. B. Bonev, E. Breukink, E. Swiezewska, B. De Kruijff, A. Watts, FASEB J. 2004, 18, 1862-9.

[48] T.-J. R. Cheng, M.-T. Sung, H.-Y. Liao, Y.-F. Chang, C.-W. Chen, C.-Y. Huang, L.-Y. Chou, Y.-D. Wu, Y.-H. Chen, Y.-S. E. Cheng, et al., Proc. Natl. Acad. Sci. U. S. A. 2008, 105, 431-6.

[49] H.-W. Shih, K.-T. Chen, T.-J. R. Cheng, C.-H. Wong, W.-C. Cheng, Org. Lett. 2011, 13, 4600-3.

[50] E. Breukink, H. E. van Heusden, P. J. Vollmerhaus, E. Swiezewska, L. Brunner, S. Walker, A. J. R. Heck, B. de Kruijff, J. Biol. Chem. 2003, 278, 19898-903.

[51] B. Schwartz, J. A. Markwalder, Y. Wang, J. Am. Chem. Soc. 2001, 123, 11638-11643.

[52] M. S. VanNieuwenhze, S. C. Mauldin, M. Zia-Ebrahimi, B. E. Winger, W. J. Hornback, S. L. Saha, J. A. Aikins, L. C. Blaszczak, J. Am. Chem. Soc. 2002, 124, 3656-3660.

[53] L.-Y. Huang, S.-H. Huang, Y.-C. Chang, W.-C. Cheng, T.-J. R. Cheng, C.-H. Wong, Angew. Chem. Int. Ed. Engl. 2014, 53, 8060-5.
[54] J. van Heijenoort, Microbiol. Mol. Biol. Rev. 2007, 71, 620-35.

[55] M. C. Lo, H. Men, A. Branstrom, J. Helm, N. Yao, R. Goldman, S. Walker, J. Amer. Chem. Soc. 2000, 122, 3540-3541.

[56] H. Brötz, M. Josten, I. Wiedemann, U. Schneider, F. Götz, G. Bierbaum, H. G. Sahl, Mol. Microbiol. 1998, 30, 317-327.

[57] T. Schneider, H.-G. Sahl, Int. J. Med. Microbiol. 2010, 300, 161-9.

[58] S. Fletcher, W. Yu, J. Huang, S. M. Kwasny, J. Chauhan, T. J. Opperman, A. D. MacKerell, E. P. H. de Leeuw, Drug Des. Devel. Ther. 2015, 9, 2383-94.

[59] B. P. Howden, J. K. Davies, P. D. R. Johnson, T. P. Stinear, M. L. Grayson, Clin. Microbiol. Rev. 2010, 23, 99-139.

[60] J. C. Barna, D. H. Williams, Annu. Rev. Microbiol. 1984, 38, 339-57.

[61] P. E. Reynolds, Eur. J. Clin. Microbiol. Infect. Dis. 1989, 8, 943-950.

[62] D. Münch, I. Engels, A. Müller, K. Reder-Christ, H. Falkenstein-Paul, G. Bierbaum, F. Grein, G. Bendas, H.-G. Sahl, T. Schneider, Antimicrob. Agents Chemother. 2015, 59, 772-81.

[63] C. G. Marshall, I. A. Lessard, I. Park, G. D. Wright, Antimicrob. Agents Chemother. 1998, 42, 2215-20.

[64] P. Courvalin, Clin. Infect. Dis. 2006, 42, S25-S34.

[65] C. T. Walsh, S. L. Fisher, I.-S. Park, M. Prahalad, Z. Wu, Chem. Biol. 1996, 3, 21-28.

[66] T. D. H. Bugg, G. D. Wright, S. Dutka-Malen, M. Arthur, P. Courvalin, C. T. Walsh, Biochemistry 1991, 30, 10408-10415. F. Van Bambeke, Curr. Opin. Investig. Drugs 2006, 7, 740-9. P. K. Linden, Expert Rev. Anti. Infect. Ther. 2008, 6, 917-928. S. J. Kim, L. Cegelski, D. Stueber, M. Singh, E. Dietrich, K. S. E. Tanaka, T. R. Parr, A. R. Far, J. Schaefer, J. Mol. Biol. 2008, 377, 281-93.

[70] L. D. Saravolatz, J. Pawlak, L. B. Johnson, Int. J. Antimicrob. Agents 2010, 36, 69-72.

[71] F. F. Arhin, D. C. Draghi, C. M. Pillar, T. R. Parr, G. Moeck, D. F. Sahm, Antimicrob. Agents Chemother. 2009, 53, 4762-71.

[72] S.-T. D. Hsu, E. Breukink, G. Bierbaum, H.-G. Sahl, B. de Kruijff, R. Kaptein, N. A. J. van Nuland, A. M. J. J. Bonvin, J. Biol. Chem. 2003, 278, 13110-7.

[73] M. R. Islam, J.-I. Nagao, T. Zendo, K. Sonomoto, Biochem. Soc. Trans. 2012, 40, 1528-33.

[74] A. Guder, I. Wiedemann, H. G. Sahl, Biopolymers 2000, 55, 62-73.

[75] N. Schnell, K.-D. Entian, U. Schneider, F. Götz, H. Zähner, R. Kellner, G. Jung, Nature 1988, 333, 276-278.

[76] G. Jung, Angew. Chemie Int. Ed. English 1991, 30, 1051-1068.

[77] A. Arguelles Arias, M. Ongena, B. Devreese, M. Terrak, B. Joris, P. Fickers, PLoS One 2013, 8, e83037.

[78] C. van Kraaij, W. M. de Vos, R. J. Siezen, O. P. Kuipers, Nat. Prod. Rep. 1999, 16, 575-87.

[79] W. C. Chan, M. Leyland, J. Clark, H. M. Dodd, L.-Y. Lian, M. J. Gasson, B. W. Bycroft, G. C. K. Roberts, FEBS Lett. 1996, 390, 129-132.

[80] H. E. Hasper, B. de Kruijff, E. Breukink, Biochemistry 2004, 43, 11567-75.

[81] I. Wiedemann, E. Breukink, C. van Kraaij, O. P. Kuipers, G. Bierbaum, B. de Kruijff, H. G. Sahl, J. Biol. Chem. 2001, 276, 17729.

[82] T. Koopmans, T. M. Wood, P. 't Hart, L. H. J. Kleijn, A. P. A. 
Hendrickx, R. J. L. Willems, E. Breukink, N. I. Martin, J. Am. Chem. Soc. 2015, 137, 9382-9.

[83] A. Ruzin, G. Singh, A. Severin, Y. Yang, R. G. Dushin, A. G Sutherland, A. Minnick, M. Greenstein, M. K. May, D. M. Shlaes, et al., Antimicrob. Agents Chemother. 2004, 48, 728-38.

[84] R. Bauer, L. M. T. Dicks, Int. J. Food Microbiol. 2005, 101, 201-216.

[85] Y. Hu, J. S. Helm, L. Chen, X.-Y. Ye, S. Walker, J. Am. Chem. Soc. 2003, 125, 8736-7.

[86] X. Yin, T. M. Zabriskie, Microbiology 2006, 152, 2969-2983.

[87] X. Fang, K. Tiyanont, Y. Zhang, J. Wanner, D. Boger, S. Walker, Mol. BioSyst. 2006, 2, 69-76.

[88] P. Cudic, J. K. Kranz, D. C. Behenna, R. G. Kruger, H. Tadesse, A. J. Wand, Y. I. Veklich, J. W. Weisel, D. G. McCafferty, Proc. Natl. Acad. Sci. U. S. A. 2002, 99, 7384-9.

[89] T. Ganz, Nat. Rev. Immunol. 2003, 3, 710-20.

[90] E. de Leeuw, C. Li, P. Zeng, C. Li, M. Diepeveen-de Buin, W.-Y. Lu, E. Breukink, W. Lu, FEBS Lett. 2010, 584, 1543-8.

[91] T. Schneider, T. Kruse, R. Wimmer, I. Wiedemann, V. Sass, U. Pag, A. Jansen, A. K. Nielsen, P. H. Mygind, D. S. Raventós, et al., Science 2010, 328, 1168-72.

[92] P. H. Mygind, R. L. Fischer, K. M. Schnorr, M. T. Hansen, C. P. Sönksen, S. Ludvigsen, D. Raventós, S. Buskov, B. Christensen, L. De Maria, et al., Nature 2005, 437, 975-80.

[93] J. S. Oeemig, C. Lynggaard, D. H. Knudsen, F. T. Hansen, K. D. Nørgaard, T. Schneider, B. S. Vad, D. H. Sandvang, L. A. Nielsen, S. Neve, et al., J. Biol. Chem. 2012, 287, 42361-72.

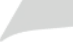

[94] M. Wilmes, B. P. A. Cammue, H.-G. Sahl, K. Thevissen, Nat. Prod. Rep. 2011, 28, 1350-8.

[95] G. Bierbaum, H. G. Sahl, Arch. Microbiol. 1985, 141, 249-54.

[96] H. J. Rogers, C. W. Forsberg, J. Bacteriol. 1971, 108, 1235-43.

[97] L. Han, A. W. Schwabacher, G. R. Moran, N. R. Silvaggi, Biochemistry 2015, 54, 7029-7040.

[98] H. He, R. T. Williamson, B. Shen, E. I. Graziani, H. Y. Yang, S. M. Sakya, P. J. Petersen, G. T. Carter, J. Am. Chem. Soc. 2002, 124, 9729-9736.

[99] Y. E. Jad, G. A. Acosta, T. Naicker, M. Ramtahal, A. El-Faham, T. Govender, H. G. Kruger, B. G. De La Torre, F. Albericio, Org. Lett. 2015, 17, 6182-6185.

[100] L. M. De Leon Rodriguez, A. J. Weidkamp, M. A. Brimble, Org. Biomol. Chem. 2015, 13, 6906-6921.

[101] C. J. White, A. K. Yudin, Nat. Chem. 2011, 3, 509-24.

[102] L. Sanière, L. Leman, J.-J. Bourguignon, P. Dauban, R. H. Dodd, Tetrahedron 2004, 60, 5889-5897.

[103] W. Craig, J. Chen, D. Richardson, R. Thorpe, Y. Yuan, Org. Lett. 2015, 17, 4620-4623.

[104] D. E. Olson, J. Y. Su, D. A. Roberts, J. Du Bois, J. Am. Chem. Soc. 2014, 1-4.

[105] S. Tsuji, K. Shoichi, T. Shiba, Chem. Lett. 1975, 1281-1284.

[106] F. von Nussbaum, R. D. Süssmuth, Angew. Chemie - Int. Ed. 2015 , 54, 6684-6.

[107] S. J. Kim, M. Singh, A. Wohlrab, T.-Y. Yu, G. J. Patti, R. D. O'Connor, M. VanNieuwenhze, J. Schaefer, Biochemistry 2013, 52, 1973-9.
[108] A. Thakkar, T. B. Trinh, D. Pei, ACS Comb. Sci. 2013, 15, 120-129.

[109] P. Cudic, D. C. Behenna, J. K. Kranz, R. G. Kruger, A. J. Wand, Y. I. Veklich, J. W. Weisel, D. G. McCafferty, Chem. Biol. 2002, 9, 897906.

[110] M.-C. Wu, M. Q. Styles, B. J. C. Law, A.-W. Struck, L. Nunns, J. Micklefield, Microbiology 2015, 161, 1338-47.

[111] M. P. Singh, P. J. Petersen, W. J. Weiss, J. E. Janso, S. W. Luckman, E. B. Lenoy, P. A. Bradford, R. T. Testa, M. Greenstein, Antimicrob. Agents Chemother. 2003, 47, 62-69.

[112] M. Adinolfi, D. Giacomini, A. Iadonisi, A. Quintavalla, S. Valerio, European J. Org. Chem. 2008, 2008, 2895-2899.

[113] R. S. Babu, S. R. Guppi, G. A. O'Doherty, Org. Lett. 2006, 8, 16058.

[114] K. S. Olivier, M. S. Van Nieuwenhze, Org. Lett. 2010, 12, 1680-3.

[115] R. G. Dushin, T.-Z. Wang, P.-E. Sum, H. He, A. G. Sutherland, J. S. Ashcroft, E. I. Graziani, F. E. Koehn, P. A. Bradford, P. J. Petersen, et al., J. Med. Chem. 2004, 47, 3487-90.

[116] P.-E. Sum, D. How, N. Torres, H. Newman, P. J. Petersen, T. S. Mansour, Bioorg. Med. Chem. Lett. 2003, 13, 2607-2610.

[117] P. J. Petersen, T. Z. Wang, R. G. Dushin, P. A. Bradford, Antimicrob. Agents Chemother. 2004, 48, 739-46.

[118] S. Fuse, H. Koinuma, A. Kimbara, M. Izumikawa, Y. Mifune, H. He, K. Shin-ya, T. Takahashi, T. Doi, J. Am. Chem. Soc. 2014, 136, 12011-7.

[119] D. G. Brown, T. L. May-Dracka, M. M. Gagnon, R. Tommasi, J. Med. Chem. 2014, 57, 10144-61.

[120] M. Cheng, J. X. Huang, S. Ramu, M. S. Butler, M. A. Cooper, Antimicrob. Agents Chemother. 2014, 58, 6819-6827.

[121] K. M. Varney, A. M. J. J. Bonvin, M. Pazgier, J. Malin, W. Yu, E. Ateh, T. Oashi, W. Lu, J. Huang, M. Diepeveen-de Buin, et al., PLoS Pathog. 2013, 9, e1003732.

[122] A. Derouaux, S. Turk, N. K. Olrichs, S. Gobec, E. Breukink, A. Amoroso, J. Offant, J. Bostock, K. Mariner, I. Chopra, et al., Biochem. Pharmacol. 2011, 81, 1098-105.

[123] I. Sosič, M. Anderluh, M. Sova, M. Gobec, I. Mlinarič Raščan, A. Derouaux, A. Amoroso, M. Terrak, E. Breukink, S. Gobec, J. Med. Chem. 2015, 58, 9712-21.

[124] D. J. Craik, D. P. Fairlie, S. Liras, D. Price, Chem. Biol. Drug Des. 2013, 81, 136-47.

[125] K. Fosgerau, T. Hoffmann, Drug Discov. Today 2014, 20, 122-128.

[126] A. D. Radkov, L. A. Moe, Appl. Microbiol. Biotechnol. 2014, 98, 5363-5374.

[127] L. Gentilucci, R. De Marco, L. Cerisoli, Curr. Pharm. Des. 2010, 16, 3185-203.

[128] D. P. McGregor, Curr. Opin. Pharmacol. 2008, 8, 616-9.

[129] H. Hinoo, T. Hattori, Y. Kimura, T. Yoshida, J. Shoji, K. Hirooka, J. Antibiot. (Tokyo). 1989, 42, 1460-1464.

[130] T. J. Oman, T. J. Lupoli, T. S. A. Wang, D. Kahne, S. Walker, W. a. Van Der Donk, J. Am. Chem. Soc. 2011, 133, 17544-17547.

[131] T. Schneider, H.-G. Sahl, Curr. Opin. Investig. Drugs 2010, 11, 15764. 
Entry for the Table of Contents (Please choose one layout)

Layout 1:

\section{MINIREVIEW}

Tackle Bac! Lipid II inhibitors, such as the recently discovered teixobactin and mannopeptimycin $\varepsilon$, offers the promise of solving the global bacterial infection crisis.

Layout 2:

\section{MINIREVIEW}

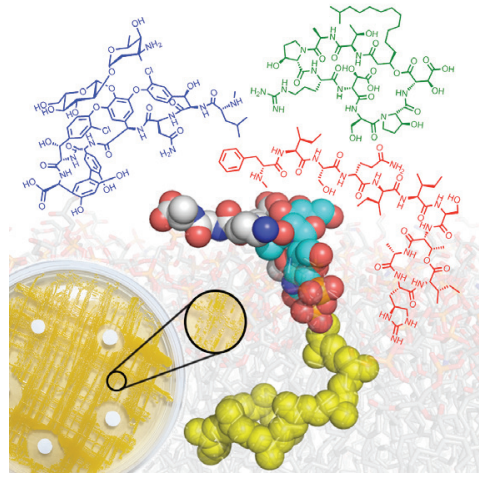

Vivian Ng and Weng C. Chan*

Page No. - Page No.

New found hope for antibiotic discovery: lipid II inhibitors
((Insert TOC Graphic here))

Text for Table of Contents
Author(s), Corresponding Author(s)*

Page No. - Page No.

Title 